\title{
Mechanochemically induced polymorphic transformations of Sofosbuvir
}

Argyro Chatziadi a,b, *, Eliška Skořepová ${ }^{a, c}$, Jan Rohlí̌̌ek ${ }^{c}$, Michal Dušek ${ }^{c}$, Luděk Ridvan ${ }^{b}$, Miroslav Šoóš ${ }^{a,}{ }^{* *}$

a Department of Chemical Engineering, University of Chemistry and Technology Prague, Technicka 3, Prague 6, Czech Republic

b Zentiva, k.s., U kabelovny 130, 10237, Prague 10, Czech Republic

c Institute of Physics of the Czech Academy of Sciences, Na Slovance 2, 18221 Praha 8, Czech Republic

Corresponding authors: * chatziaa@vscht.cz,** miroslav.soos@vscht.cz 
Table S1 Crystallographic data and details of refinements of sofosbuvir form 1.

\begin{tabular}{|c|c|}
\hline Formula & $\mathrm{C}_{22} \mathrm{H}_{29} \mathrm{~N}_{3} \mathrm{O}_{9} \mathrm{P}_{1} \mathrm{~F}_{1}$ \\
\hline Formula weight $\left(\mathrm{g} \mathrm{mol}^{-1}\right)$ & 529.46 \\
\hline Temperature $(\mathrm{K})$ & 95 \\
\hline Wavelength $(\AA)$ & 1.54184 \\
\hline Crystal System & Monoclinic \\
\hline Space group & $P 2_{1}$ \\
\hline \multicolumn{2}{|l|}{ Unit cell dimensions } \\
\hline$a(\AA)$ & $20.0741(4)$ \\
\hline$b(\AA)$ & $6.09630(10)$ \\
\hline$c(\AA)$ & $23.0346(4)$ \\
\hline$\alpha\left(^{\circ}\right)$ & 90 \\
\hline$\beta\left(^{\circ}\right)$ & $112.276(2)$ \\
\hline$\gamma\left({ }^{\circ}\right)$ & 90 \\
\hline Cell volume $\left(\AA^{3}\right)$ & $2608.54(5)$ \\
\hline $\mathrm{Z}$ & 4 \\
\hline Absorption coefficient $\left(\mathrm{mm}^{-1}\right)$ & 1.477 \\
\hline Crystal size (mm) & $0.023 \times 0.038 \times 0.200$ \\
\hline Absorption correction & Multi-scan \\
\hline Measured reflections & 22610 \\
\hline Independent reflections/ reflections $\left[F^{2}>\right.$ & 10325,9575 \\
\hline \multicolumn{2}{|l|}{$\left.2 \sigma\left(F^{2}\right)\right]$} \\
\hline Data/restraints/parameters & $10325 / 93 / 686$ \\
\hline Goodness-of-fit (all data) & 0.9347 \\
\hline Final indices & $\mathrm{R}_{1}=0.0378, \mathrm{wR}_{2}=0.0838$ \\
\hline \multicolumn{2}{|l|}{$R\left[F^{2}>2 \sigma\left(F^{2}\right)\right], w R\left(F^{2}\right)$} \\
\hline $\mathrm{R}$ indices (all data) & $\mathrm{R}_{1}=0.0420, \mathrm{wR}_{2}=0.0868$ \\
\hline$\Delta \rho_{\max } / \Delta \rho_{\min }\left(\mathrm{e} . \AA^{-3}\right)$ & $0.41 /-0.39$ \\
\hline
\end{tabular}




\section{Details for crystal structure solution of forms A and B}

Crystal structure solution and refinement from Powder X-ray Diffraction (PXRD) data was identical for both forms A and B. The ab initio structure solution including indexing and space group search was performed in FOX software ${ }^{1}$. The model of the sofosbuvir molecule was taken from the crystal structure of Sofosbuvir form 1 . The best solution was taken for the Rietveld refinement in Jana2006 software ${ }^{2}$. During the refinement hydrogen atoms were kept in their calculated positions. For other atoms, geometrical restraints for bond and bond-angles had to be used to keep a reasonable geometry of the molecule. At the final stage of the refinement, all nonhydrogen atomic positions were refined using 38 bond and 56 bond-angle restraints, together with one shared isotropic atomic displacement parameter (ADP), unit cell parameters, background and profile parameters. The final agreement factors for Form A are $R_{w p}=7.46 \%$ and $R_{p}=5.26 \%$ and for Form B are $R_{w p}=2.54 \%$ and $R_{p}=1.88 \%$. The quality of the powder diffraction pattern of the Form B was significantly better than of the Form A. The reflections of Form A were broader with wider Lorentzian peak tails and with anisotropic peak broadening. The difference Fourier map does not indicate any strong maximum or minimum. It contains some indications of possible disorder - minima around atomic positions and several maxims out of the molecule. However, the resolution of the difference Fourier map is low, as it is usual for laboratory XRPD data, and its interpretation seems to be impossible, see Figure SI 1. Insufficient description of all these effects resulted in higher agreements factors in the case of Form A. 
Table S1a Crystallographic data and details of refinements of sofosbuvir form A and B.

\begin{tabular}{|c|c|c|}
\hline & Form A & Form B \\
\hline Formula & $\mathrm{C}_{22} \mathrm{H}_{29} \mathrm{~N}_{3} \mathrm{O}_{9} \mathbf{P}_{1} \mathrm{~F}_{1}$ & $\mathrm{C}_{22} \mathrm{H}_{29} \mathrm{~N}_{3} \mathrm{O}_{9} \mathbf{P}_{1} \mathrm{~F}_{1}$ \\
\hline Formula weight $\left(\mathrm{g} \mathrm{mol}^{-1}\right)$ & 529.5 & 529.5 \\
\hline Temperature (K) & 298 & 298 \\
\hline Wavelength $(\AA)$ & 1.54184 & 1.54184 \\
\hline Crystal System & Orthorhombic & Monoclinic \\
\hline Space group & $P 2_{1} 2_{1} 2_{1}$ & $P 2_{1}$ \\
\hline$a(\AA)$ & $28.0131(18)$ & $14.4908(2)$ \\
\hline$b(\AA)$ & $17.0659(8)$ & $17.0324(2)$ \\
\hline$c(\AA)$ & $5.2519(2)$ & $5.23265(6)$ \\
\hline$\alpha\left(^{\circ}\right)$ & 90 & 90 \\
\hline$\beta\left(^{\circ}\right)$ & 90 & $100.5255(14)$ \\
\hline$\gamma\left({ }^{\circ}\right)$ & 90 & 90 \\
\hline Cell volume $\left(\AA^{3}\right)$ & $2510.8(2)$ & $1269.76(3)$ \\
\hline $\mathrm{Z}$ & 4 & 2 \\
\hline Absorption coefficient $\left(\mathrm{mm}^{-1}\right)$ & 1.53 & 1.52 \\
\hline Measured range, step & $4^{\circ}-80^{\circ} 2 \theta, 0.013^{\circ} 2 \theta$ & $4^{\circ}-80^{\circ} 2 \theta, 0.013^{\circ} 2 \theta$ \\
\hline parameters/restraints/constraints & $149 / 94 / 151$ & $145 / 94 / 152$ \\
\hline Goodness-of-fit (all data) & 9.55 & 2.61 \\
\hline$R p / R w p / \operatorname{Rexp}$ & $0.053 / 0.075 / 0.008$ & $0.019 / 0.025 / 0.01$ \\
\hline $\mathrm{R}(\mathrm{F}) / \chi^{2}$ & $0.065 / 91.2$ & $0.059 / 6.81$ \\
\hline$\Delta \rho_{\max } / \Delta \rho_{\min }\left(\mathrm{e} . \AA^{-3}\right)$ & $0.29 /-0.28$ & $0.27 /-0.23$ \\
\hline
\end{tabular}




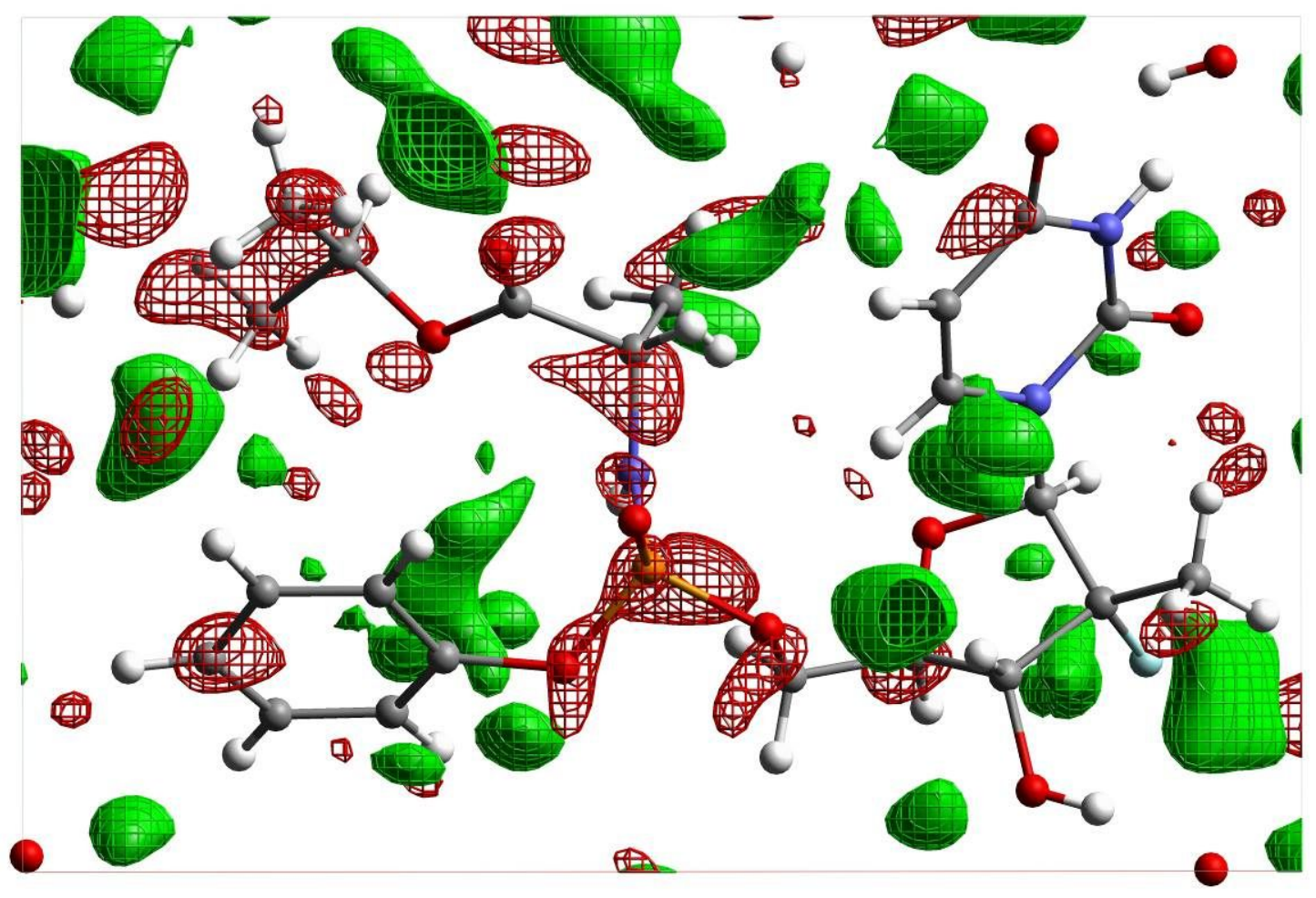

Figure SI 1. Difference Fourier map of the Form A around the molecule of sofosbuvir. Red is negative map at $-0.15 \mathrm{e} / \AA^{3}$ and green is positive at $0.15 \mathrm{e} / \AA^{3}$. 


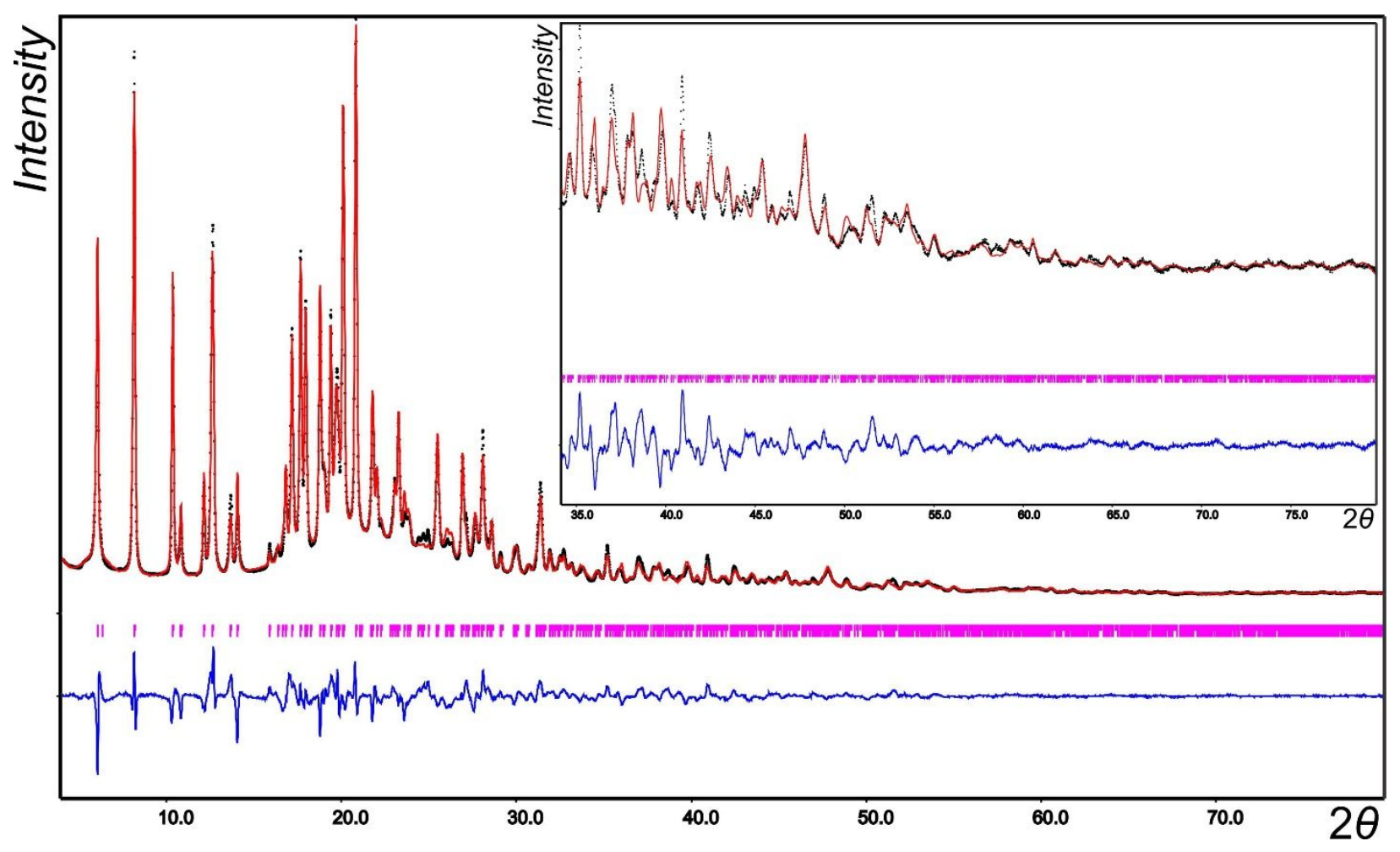

Figure SI 2. Final Rietveld plot of the Form A. Black dots - measured data, red line - calculated profile, blue line - difference curve, magenta vertical bars - position of Bragg reflections.

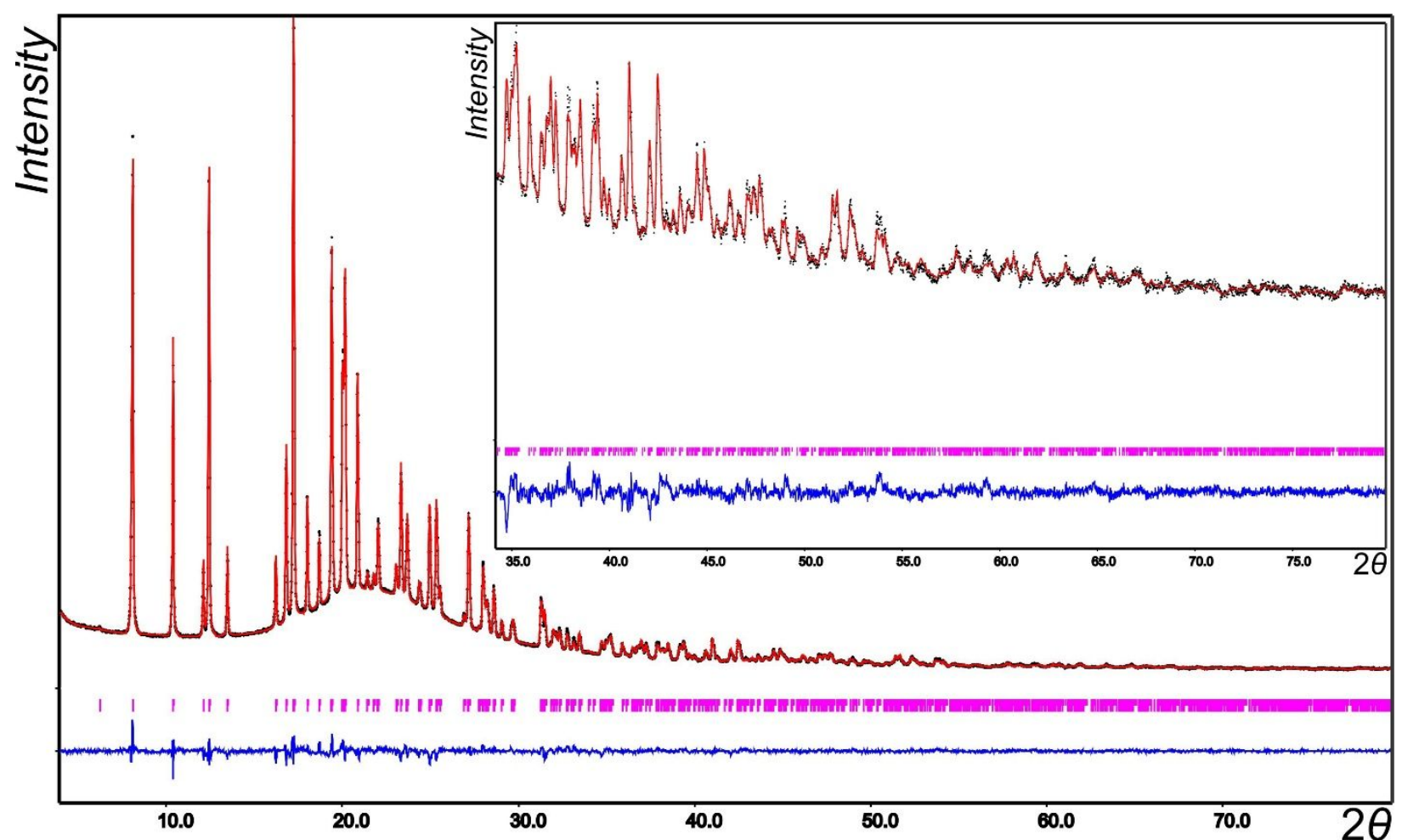

Figure SI 3. Final Rietveld plot of the Form B. Black dots - measured data, red line - calculated profile, blue line - difference curve, magenta vertical bars - position of Bragg reflections. 


\section{Details of indexing and le Bail fitting of the Form V}

The diffraction pattern was indexed in the program Conograph ${ }^{3}$ with results $M(20)=30$. The consequent le Bail fitting confirmed the unit cell, with results $a=17.8062(9) \AA, b=6.1162(3) \AA$, $c=13.8501(8) \AA, \beta=108.170(5)^{\circ}, \mathrm{V}=1433.14(14) \AA^{3}$. The double unit cells were also tested in all three directions, but with any significant improvement of the profile fit.

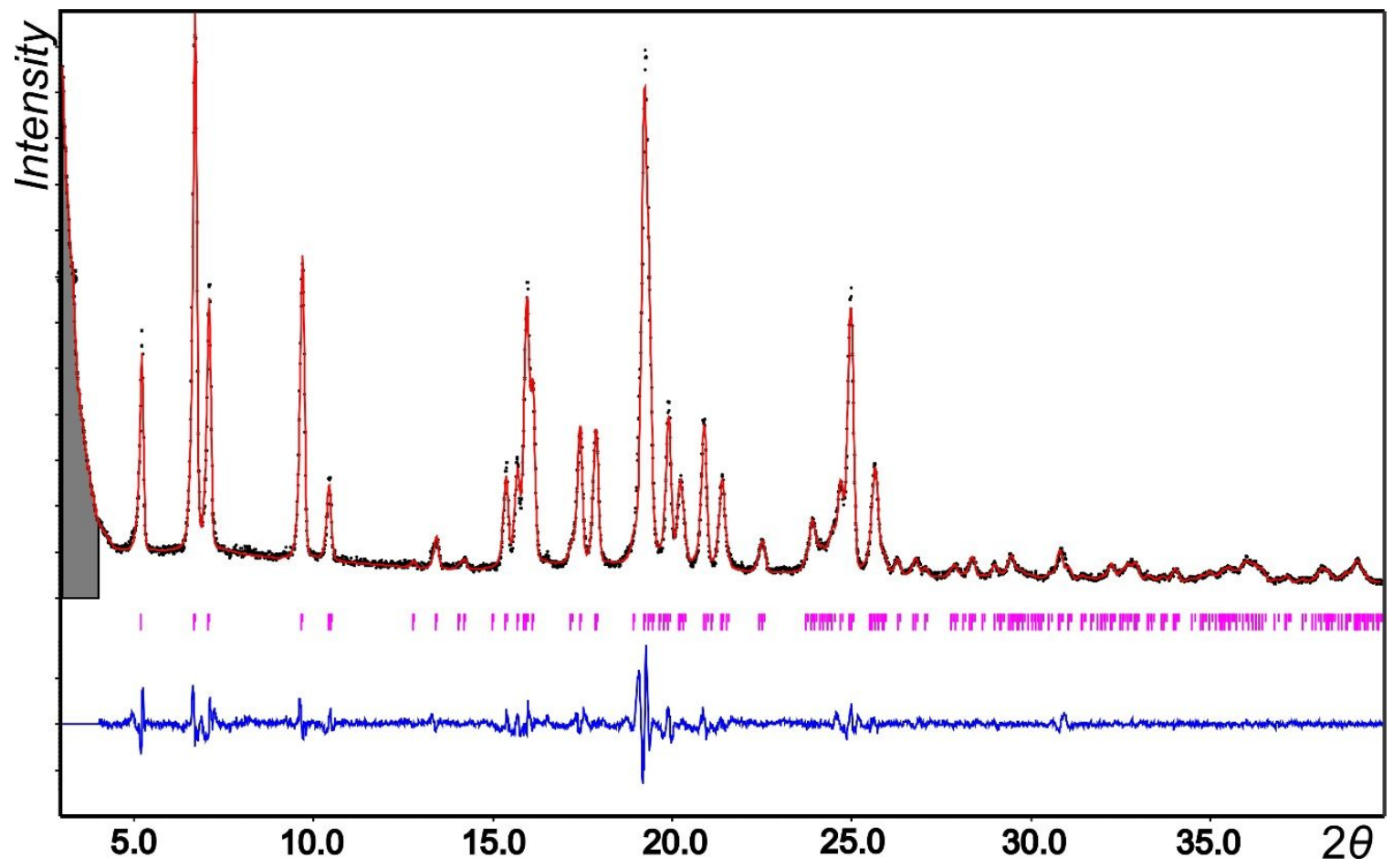

Figure SI 4. Le Bail fit of the Form V. Black dots - measured data, red line - calculated profile, blue line - difference curve, magenta vertical bars - position of Bragg reflections. 
DSC OF THE VARIOUS POLYMORPHS

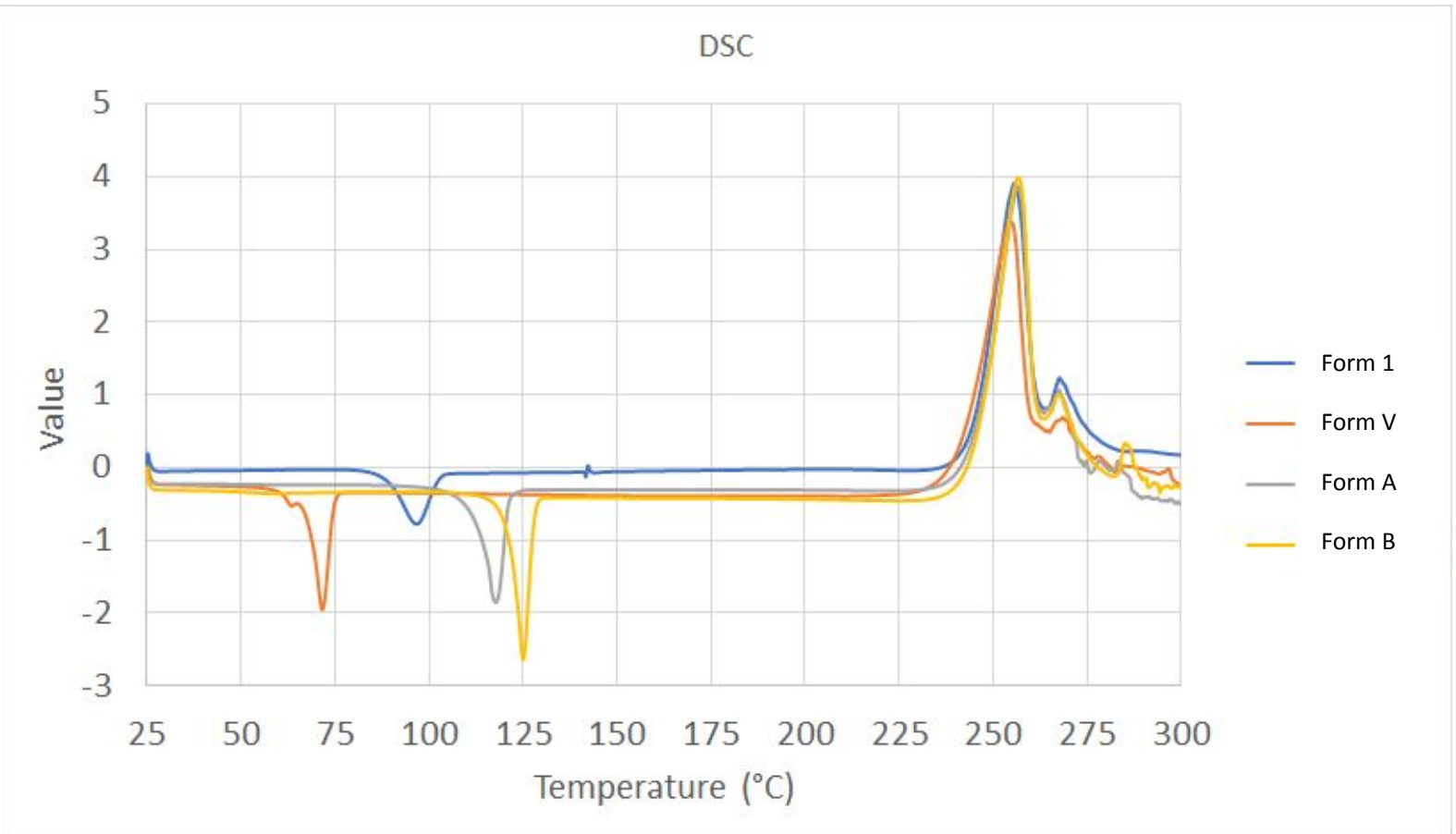

Figure SI 5. Melting points of forms 1, A, B and V of sofosbuvir.

Table S2. Melting temperatures of the polymorphs 1, A, B as well as the solvated form V of sofosbuvir

\begin{tabular}{lc}
\hline Form & $\mathrm{T}_{\mathrm{m}}\left({ }^{\circ} \mathrm{C}\right)$ \\
\hline 1 & 96.57 \\
$\mathrm{~V}$ & 71.54 \\
$\mathrm{~A}$ & 117.90 \\
$\mathrm{~B}$ & 124.83 \\
\hline
\end{tabular}

\section{Tg (GLASS TRANSITION TEMPERATURE) OF THE AMORPHOUS SOFOSBUVIR}

the $\mathrm{Tg}$ for amorphous Sofosbuvir was investigated and it was found to be around $50^{\circ} \mathrm{C}\left(\mathrm{RVO}=49^{\circ} \mathrm{C}\right.$, $\mathrm{HME}=45^{\circ} \mathrm{C}$, prediction $\mathrm{DSC}=60^{\circ} \mathrm{C}$ ) . 
FORM V- TGA

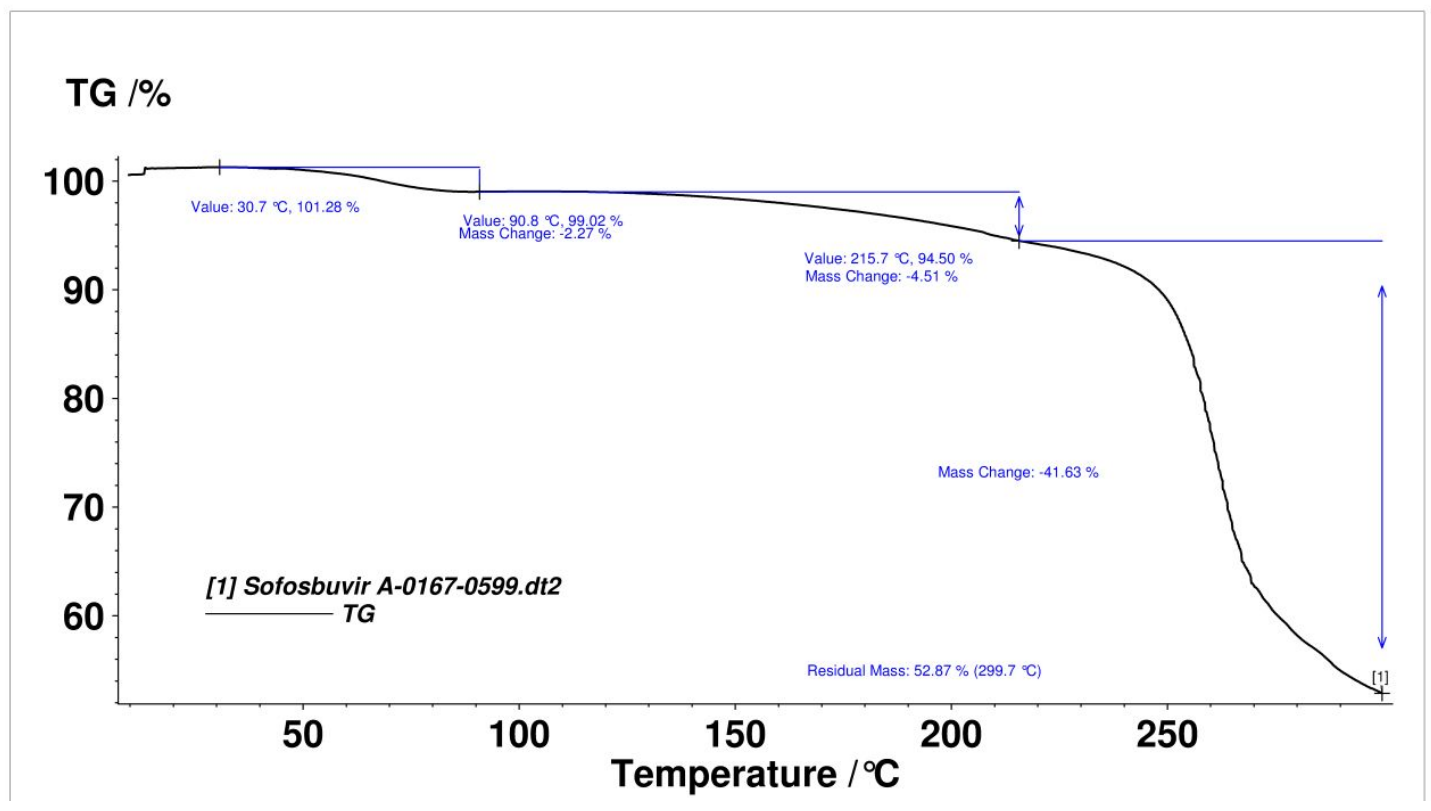

Figure SI 6. TGA of solvated form V of sofosbuvir. 
EFFECT OF EXPERIMENTAL CONDITIONS ALL THE RESULTS

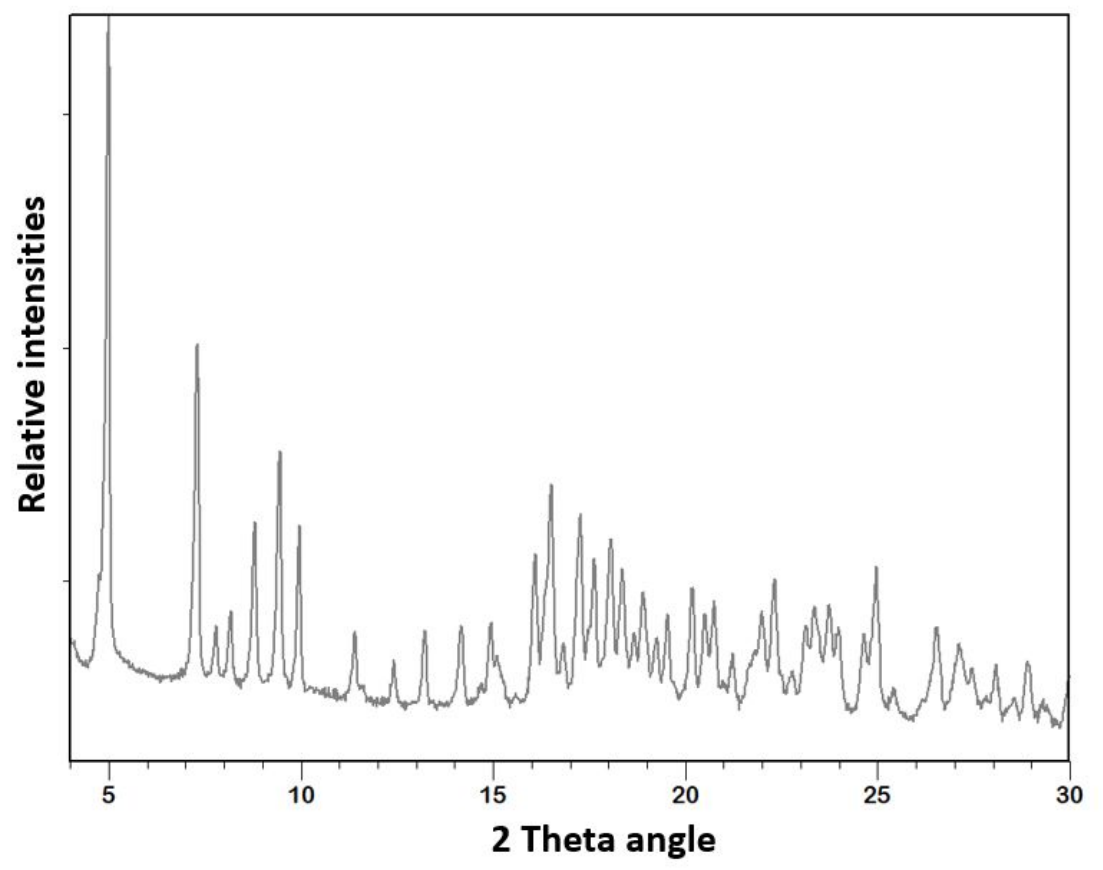

Figure SI 7. Measured diffraction pattern of form 1. 


\section{Effect of different liquid additives}

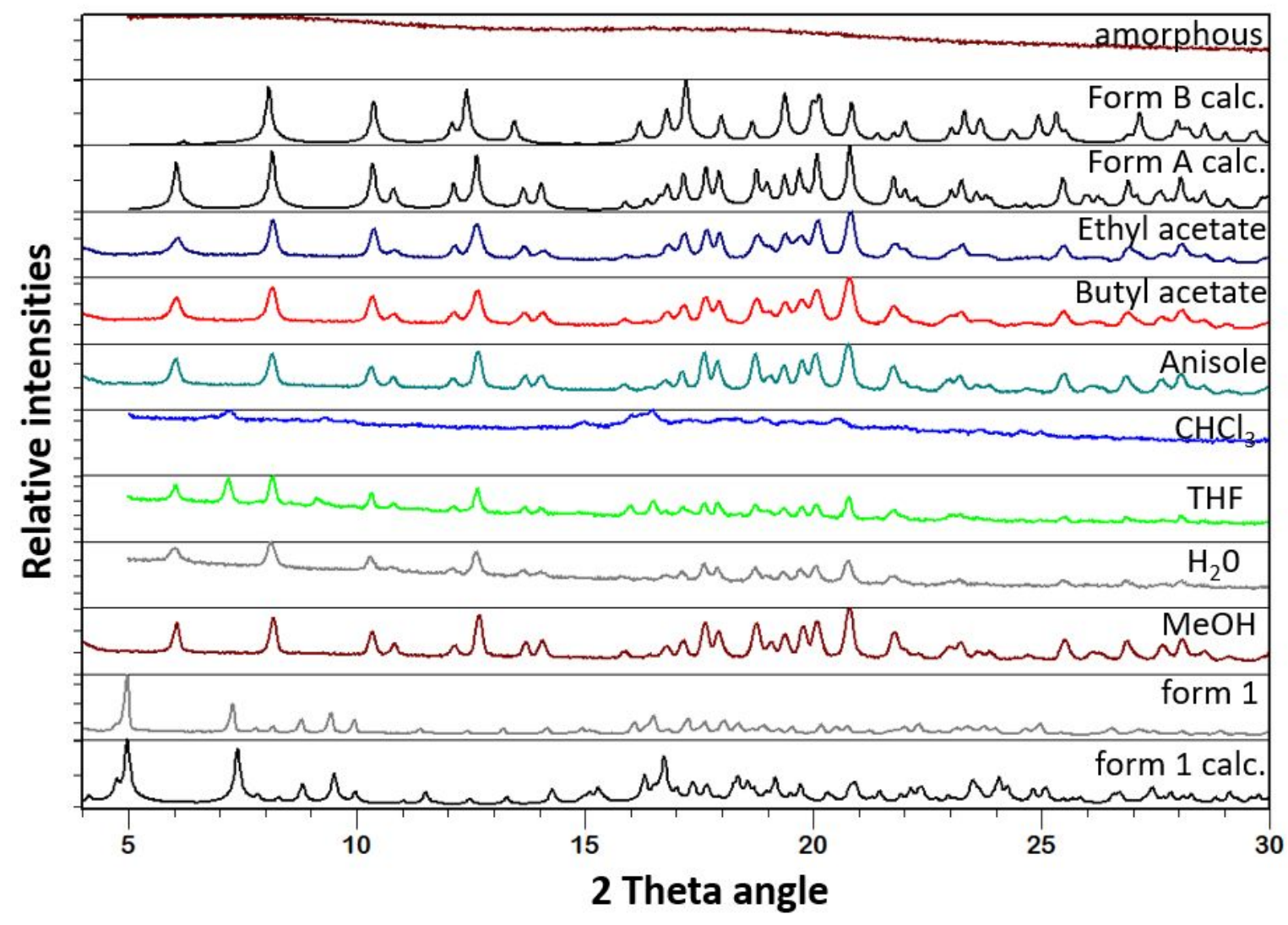

Figure SI 8. Effect of different liquid additives after $30 \mathrm{~min}$ of milling for $(\eta=0.1 \mu \mathrm{l} / \mathrm{mg})$. Measured and calculated patterns. For forms $\mathrm{MeOH}$ and $\mathrm{H}_{2} \mathrm{O}$ the patterns are after the fast recrystallization that occurred. 


\section{Effect of time}

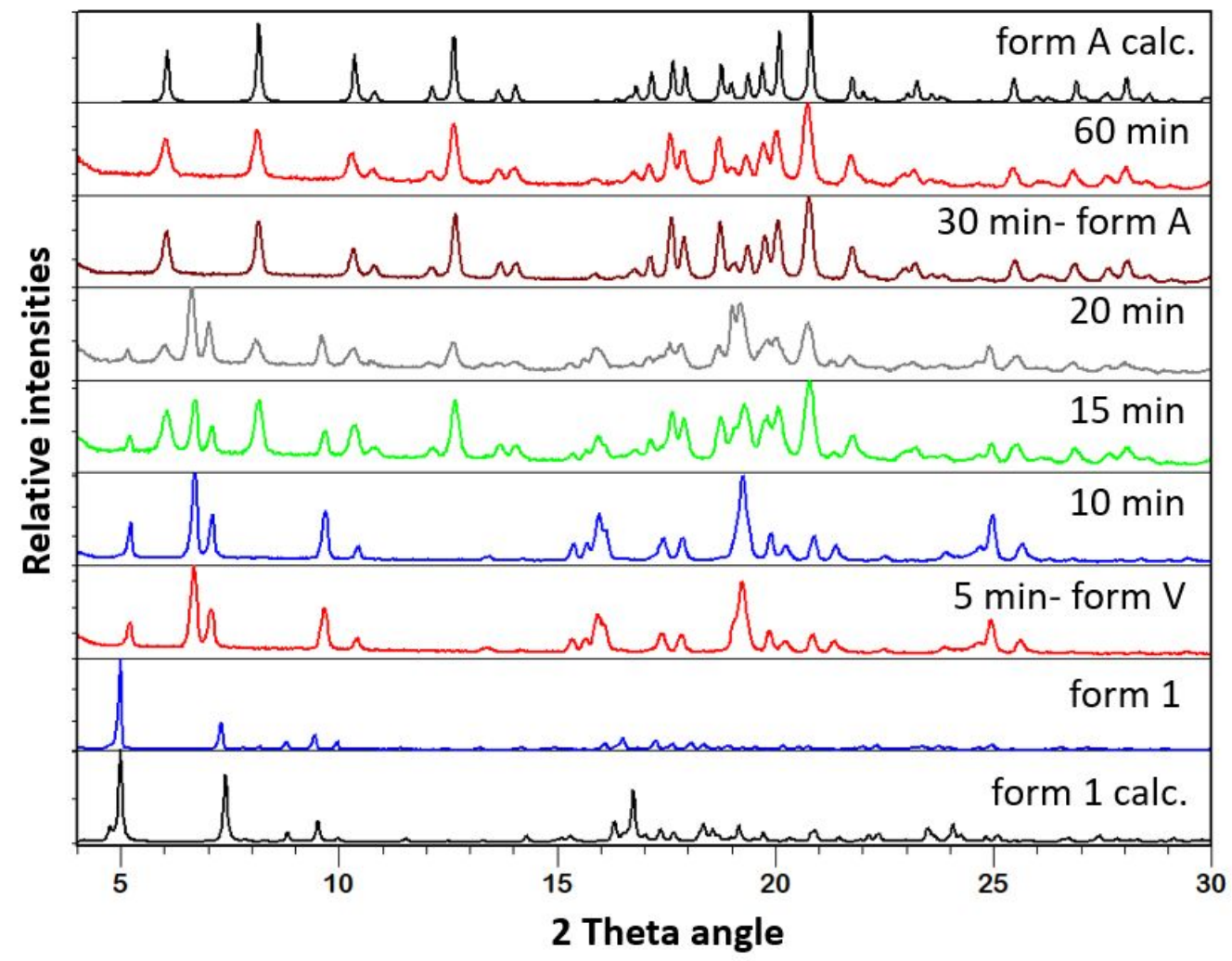

Figure SI 9. PXRD patterns of sofosbuvir after LAG with anisole after 5, 10, 15, 20, 30 and 60 $\min$ and for $\eta=0.2$. The transformation proceeds through form $\mathrm{V}$. 


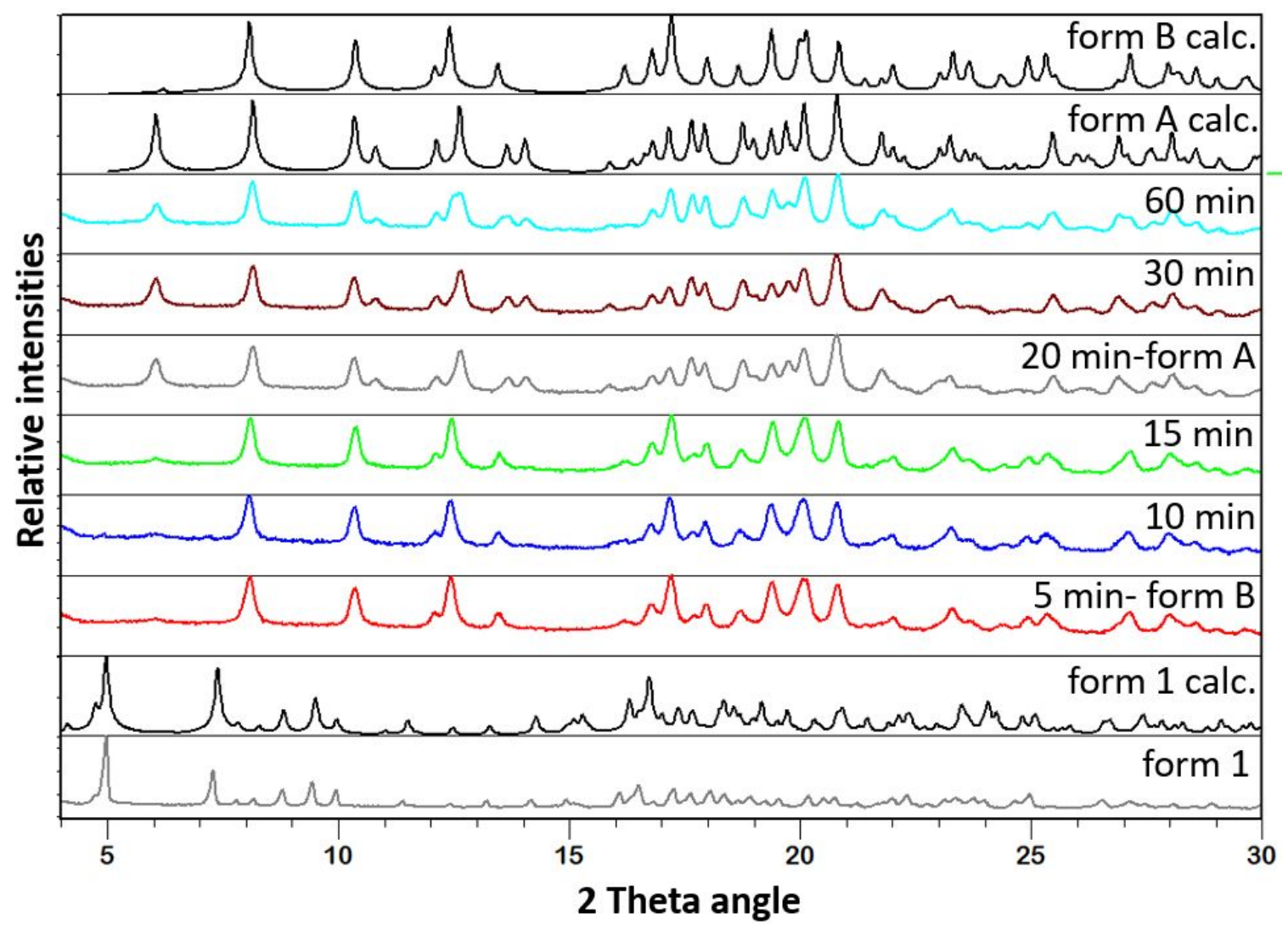

Figure SI 10. PXRD patterns of sofosbuvir after LAG with butyl acetate after LAG with anisole after 5, 10, 15, 20, 30 and $60 \mathrm{~min}$ and for $\eta=0.2$. The transformation proceeds through form B. 


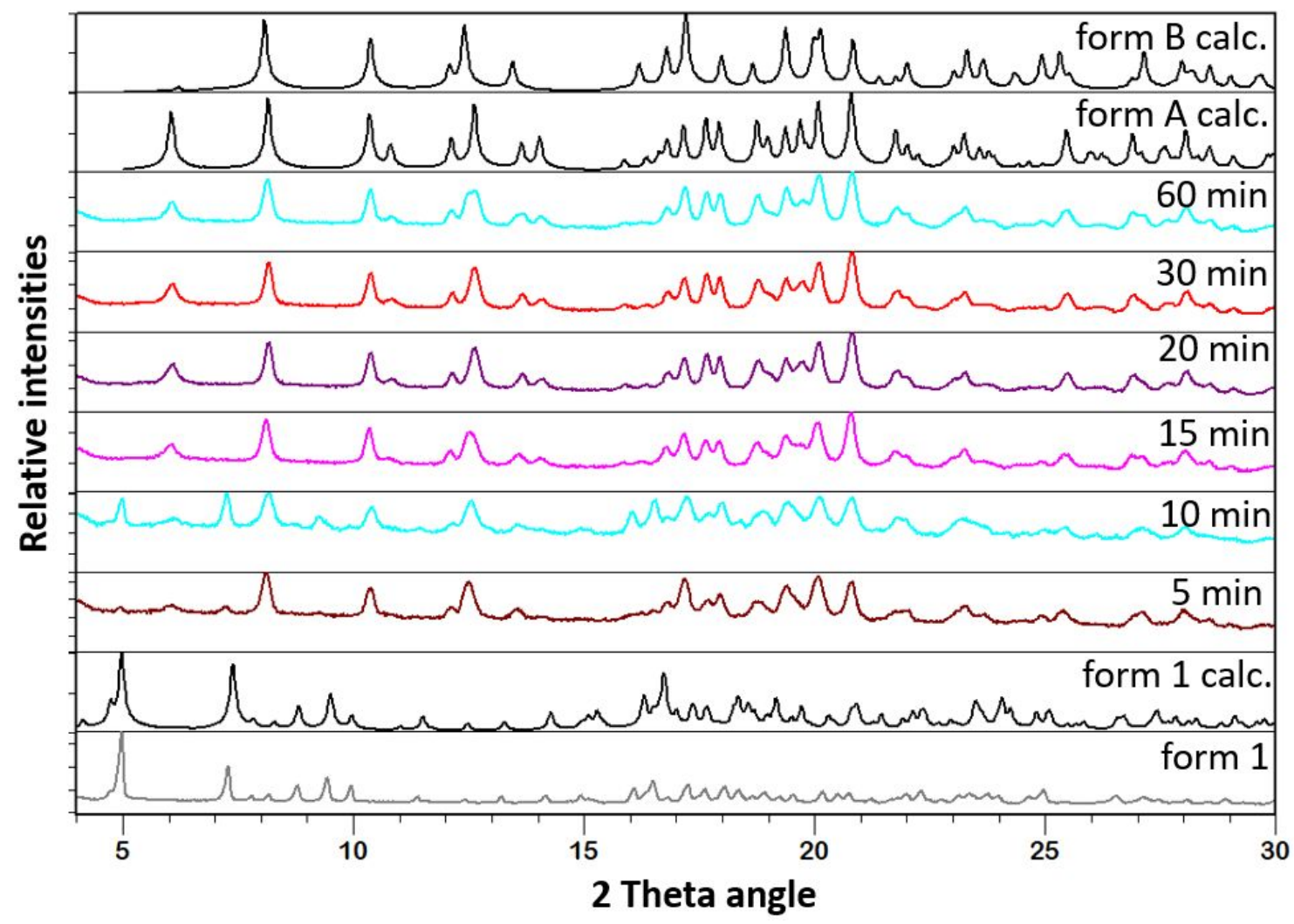

Figure SI 11. PXRD patterns of sofosbuvir after LAG with ethyl acetate after 5, 10, 15, 20, 30 and $60 \mathrm{~min}$ and for $\eta=0.2$. The transformation proceeds through form $B$. 


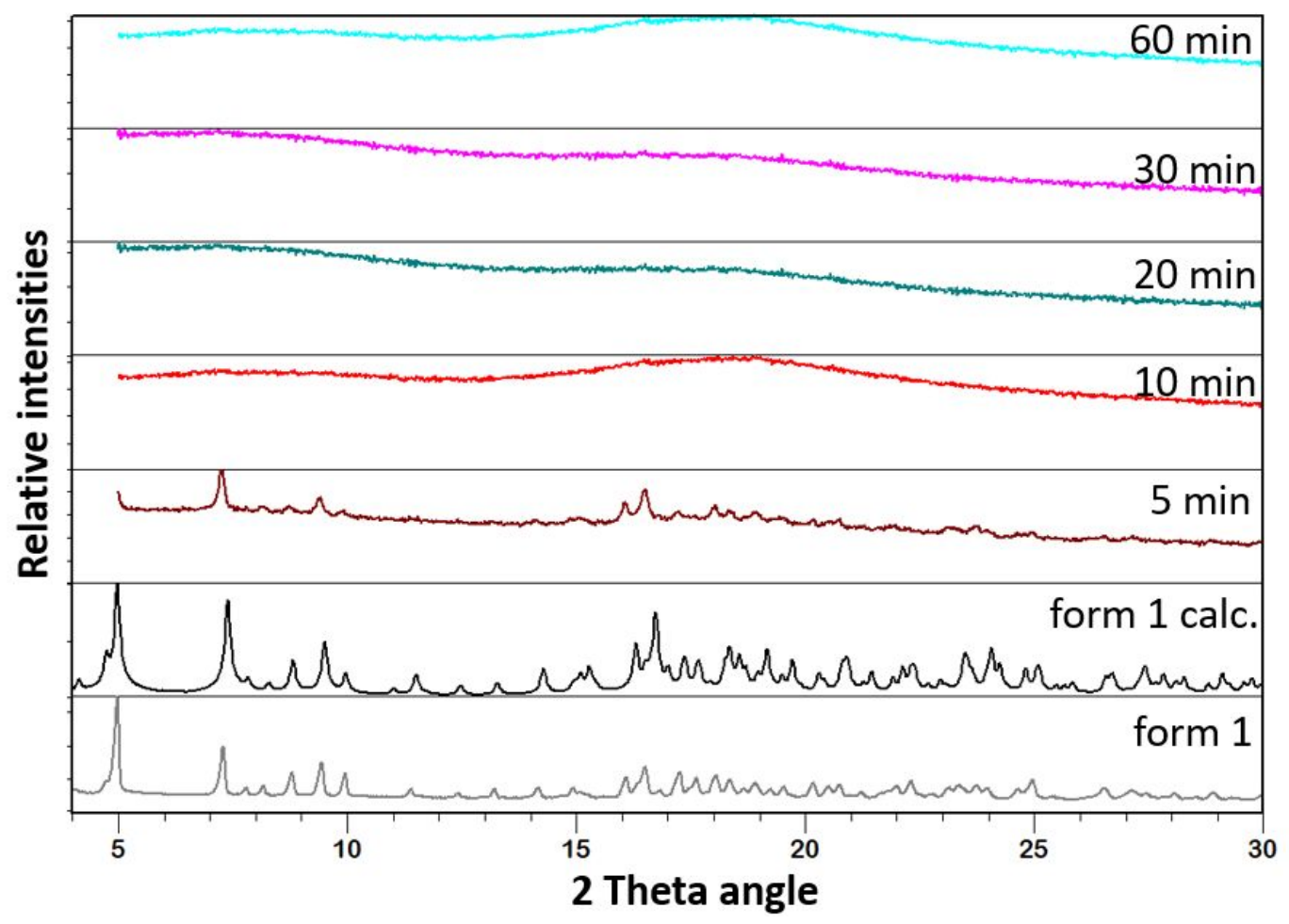

Figure SI 12. Obtained patterns after milling with acetone for 5, 10, 20, 30,60 $\min$ and for $\eta=$ 0.2 . 


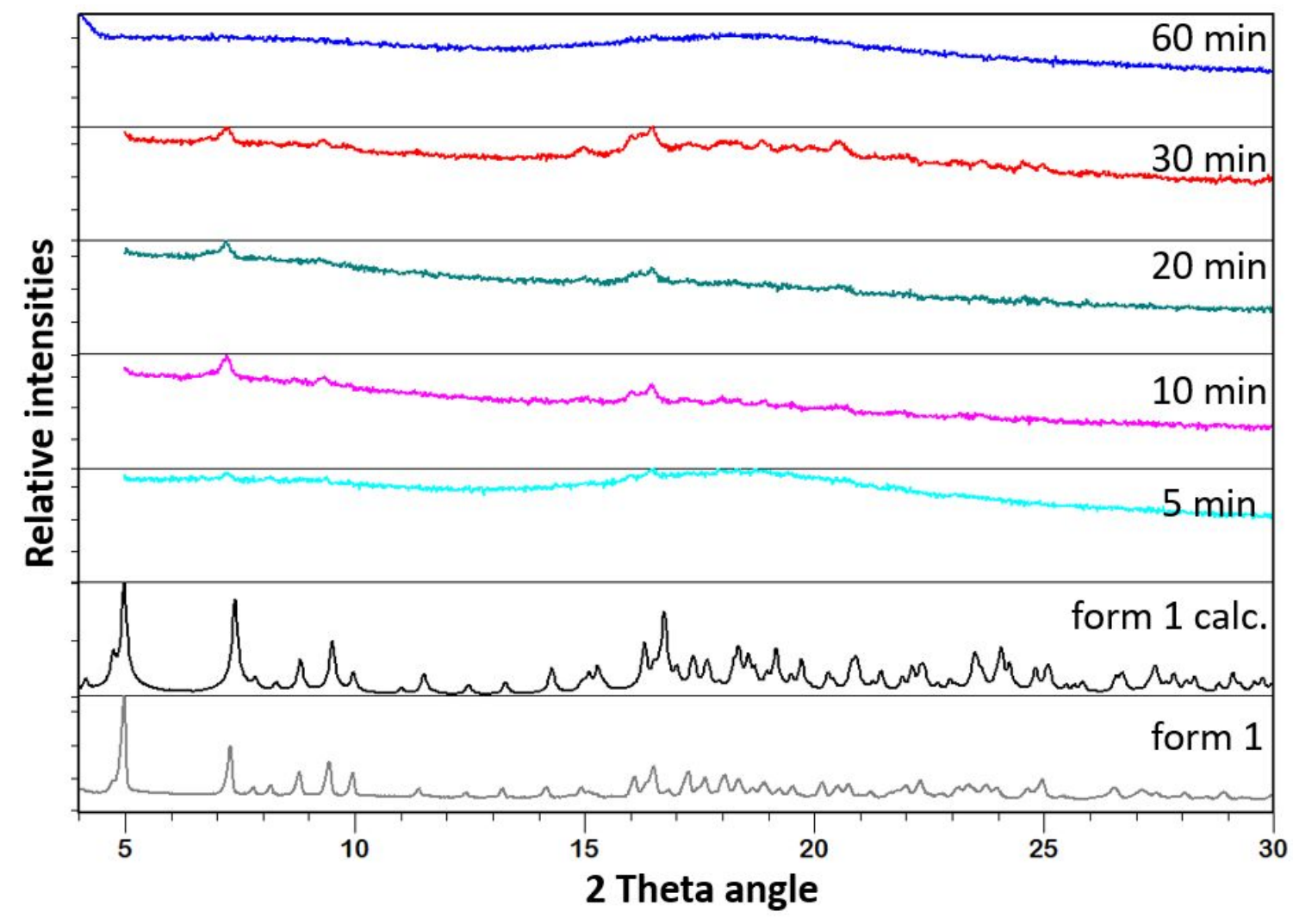

Figure SI 13. Obtained patterns after milling with chloroform for 5, 10, 20, 30,60 min and for $\eta$ $=0.2$. 


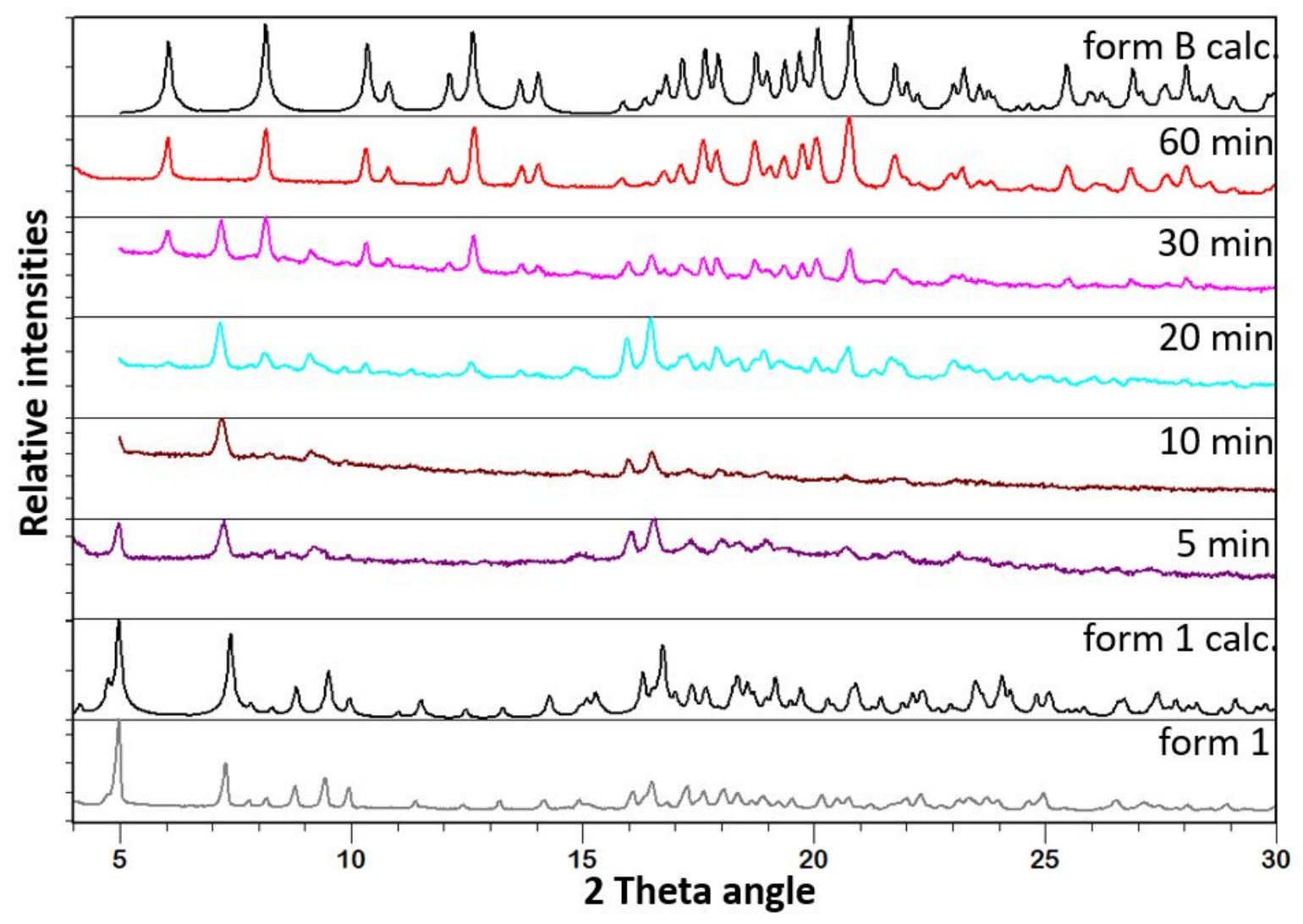

Figure SI 14. Obtained patterns after milling with $\mathrm{THF}$ for $5,10,20,30,60 \mathrm{~min}$ and for $\eta=0.2$. 


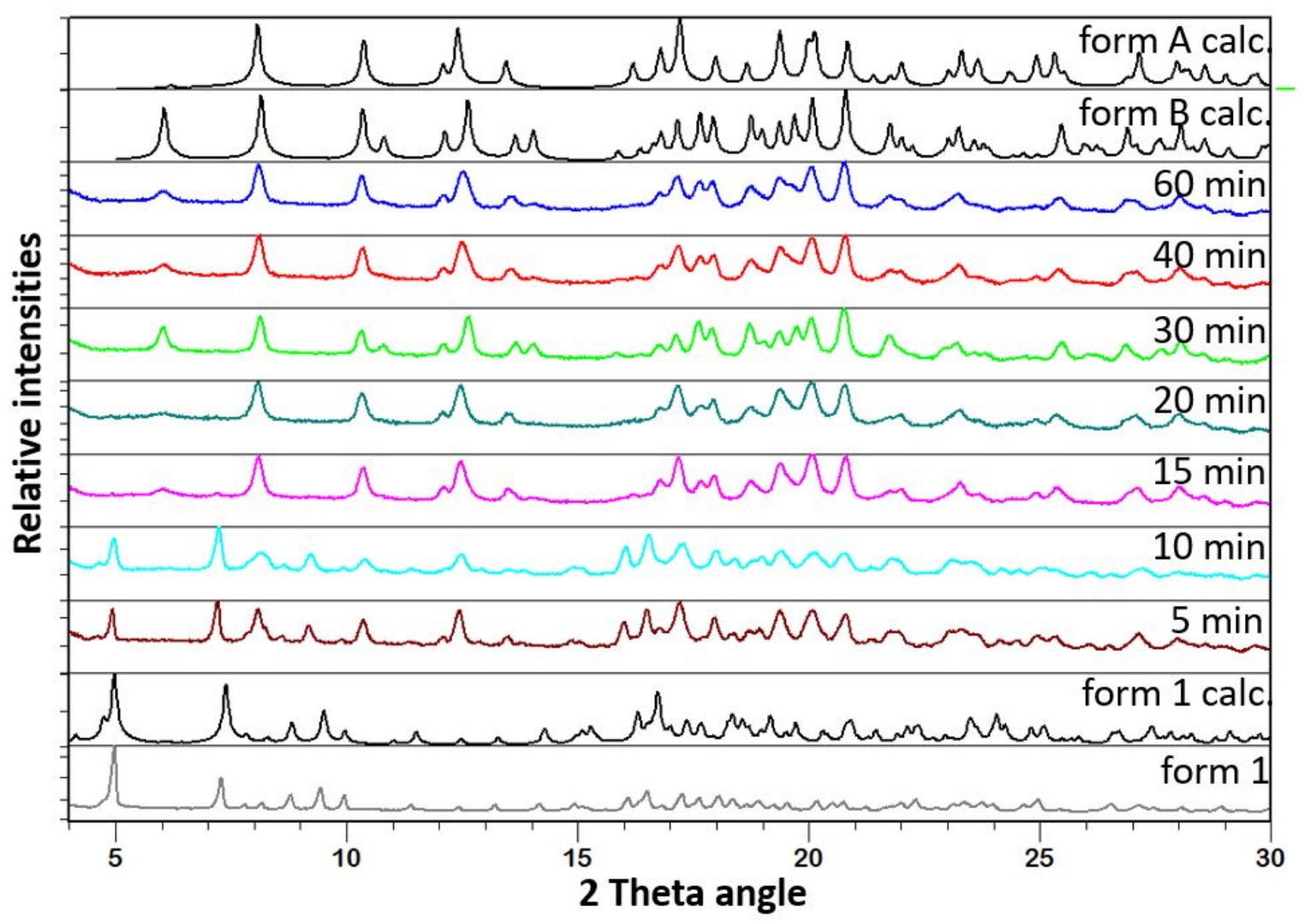

Figure SI 15. Kinetics of polymorphic transformation with butyl acetate for $n=0.1$ and various milling periods. 


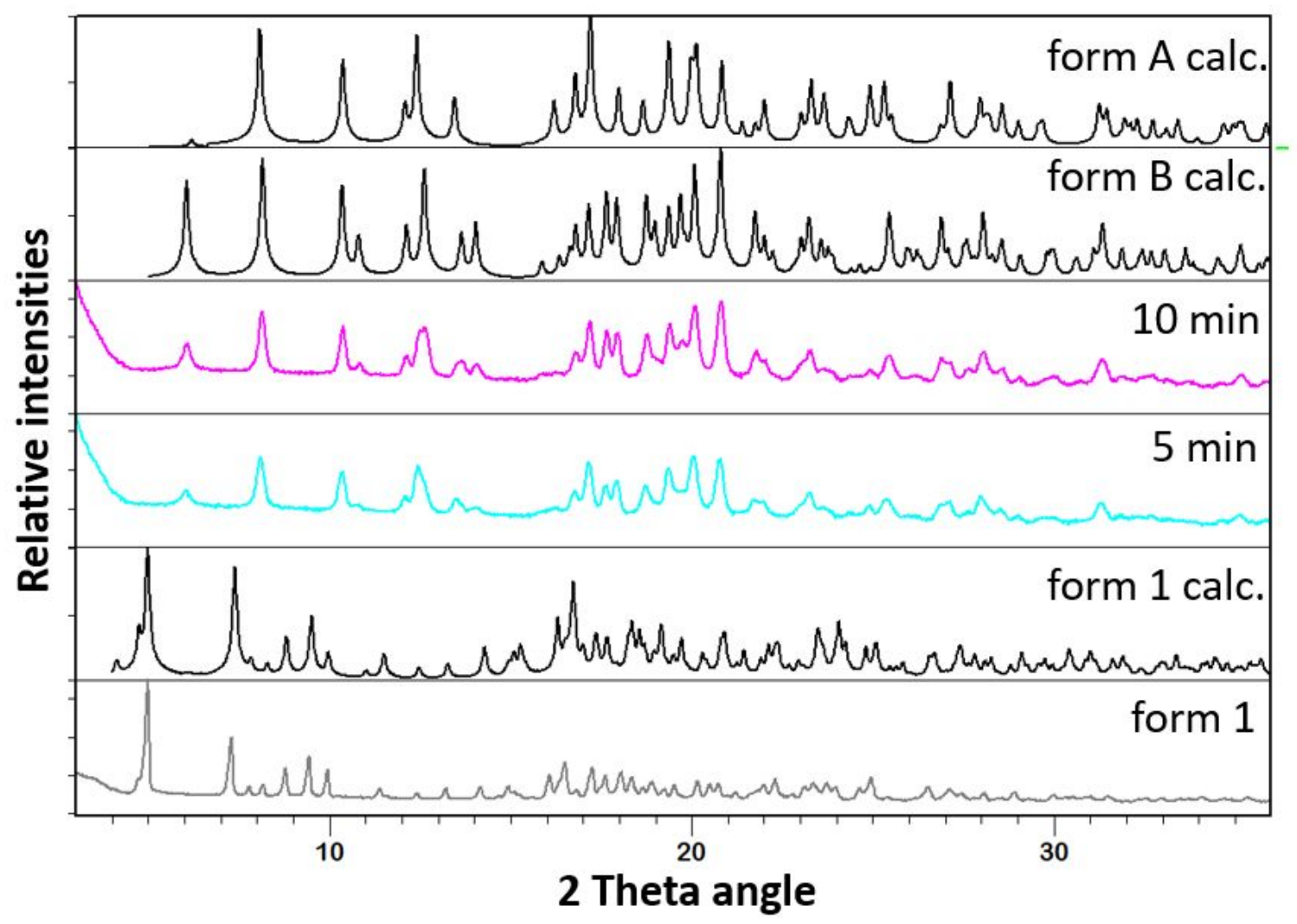

Figure SI 16. Kinetics of polymorphic transformation with butyl acetate for $n=0.5$. 


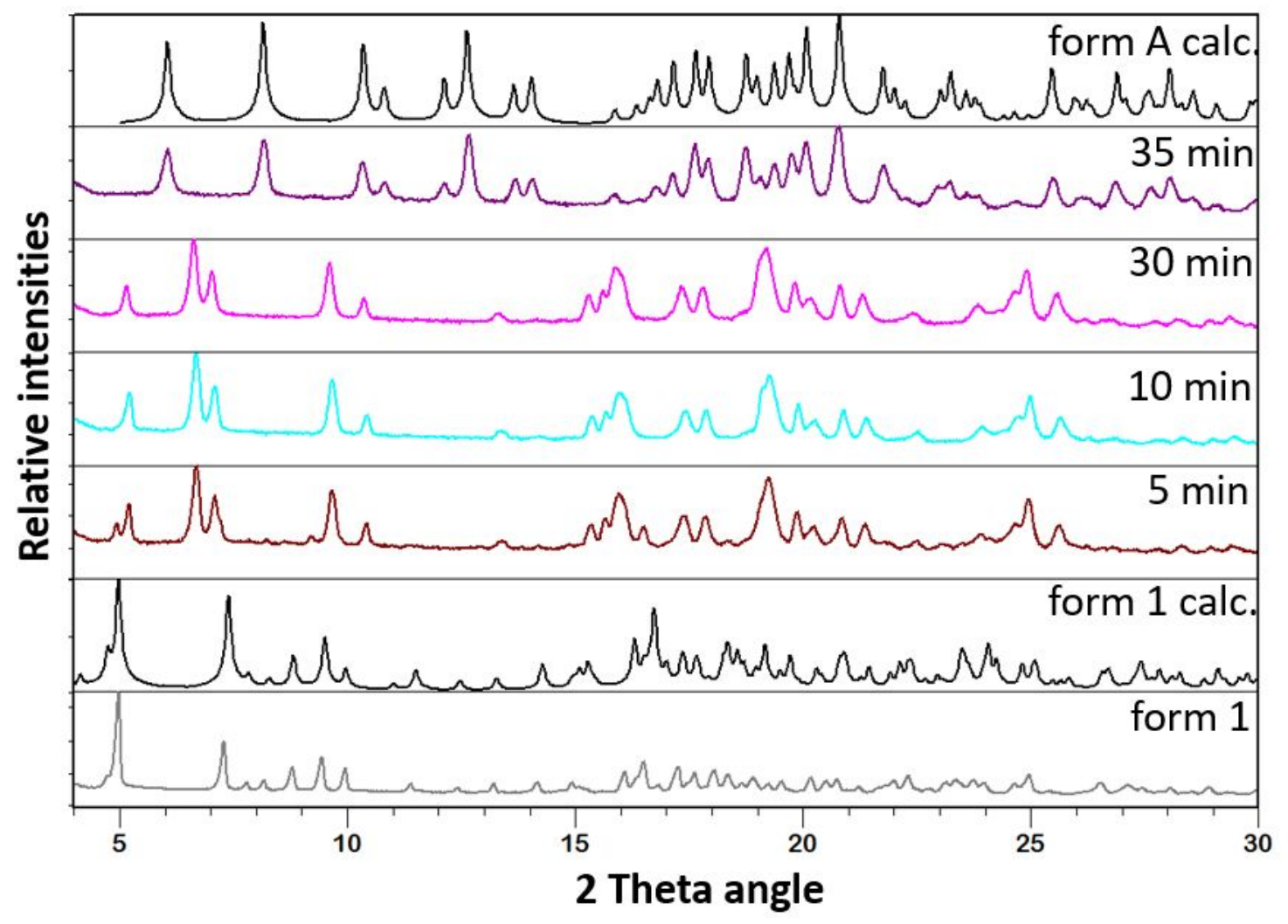

Figure SI 17. Kinetics of polymorphic transformation with anisole for $\eta=0.1 \mu 1 / \mathrm{mg}$. 


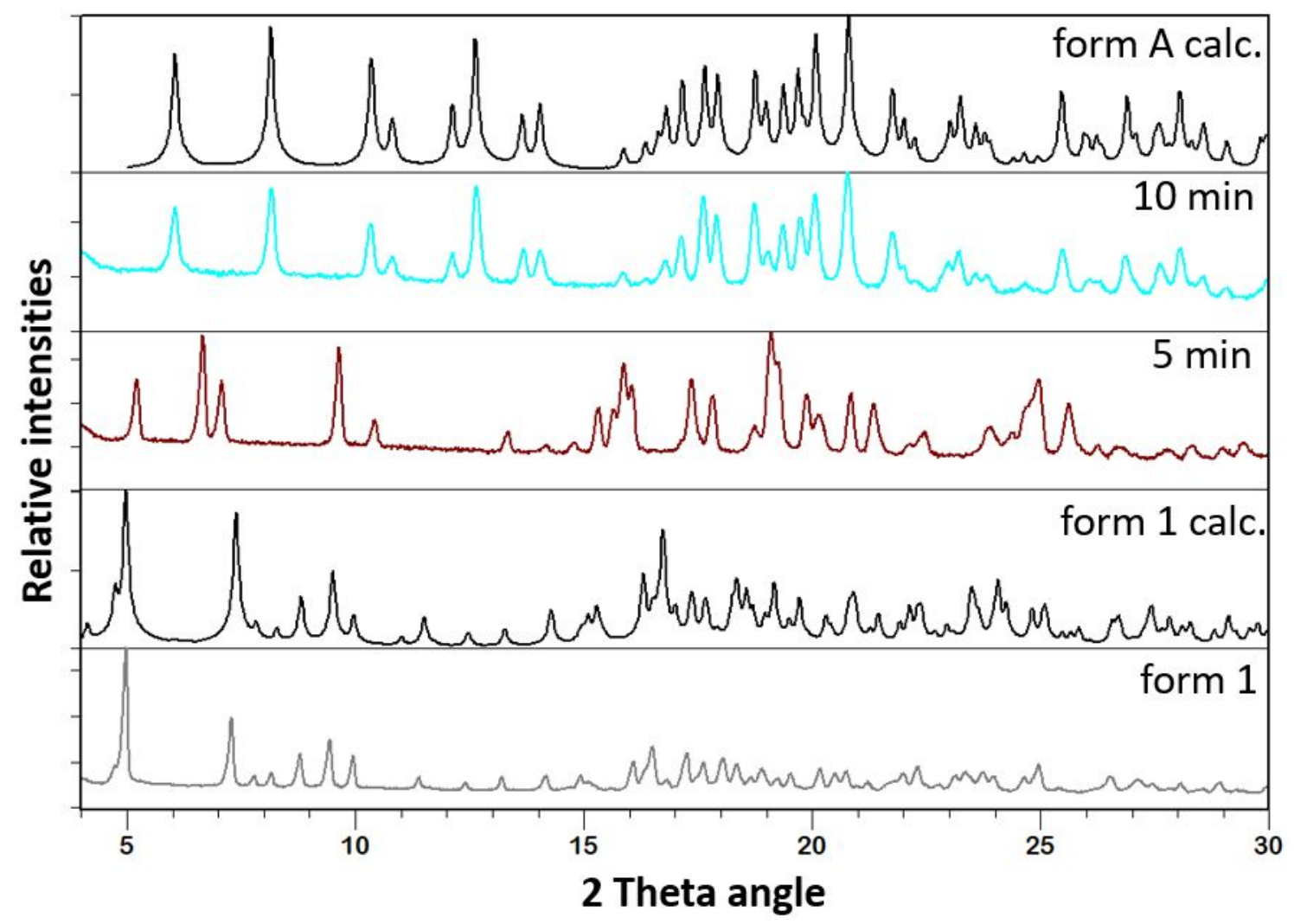

Figure SI 18. Kinetics of polymorphic transformation with anisole for $\eta=0.4 \mu 1 / \mathrm{mg}$. 
Tables S3. Results from hydrogen bonding propensities calculations.

\begin{tabular}{lll}
\hline WATER & & \\
O40 of water & O10 of phosphonate & 0.91 \\
O26 of cyclic_hydroxyl & O10 of phosphonate & 0.84 \\
N11 of phosphinic_amide & O10 of phosphonate & 0.82 \\
N33 of cyclic_amide_2 & O10 of phosphonate & 0.8 \\
O40 of water & O39 of cyclic_amide_2 & 0.66 \\
O40 of water & O40 of water & 0.62 \\
O40 of water & O17 of acyclic_ester & 0.55 \\
O40 of water & O26 of cyclic_hydroxyl & 0.55 \\
O40 of water & O38 of cyclic_amide_2 & 0.52 \\
O26 of cyclic_hydroxyl & O39 of cyclic_amide_2 & 0.51 \\
\hline
\end{tabular}

\section{METHANOL}

N11 of phosphinic_amide

O10 of phosphonate

0.87

O41 of acyclic_hydroxyl

O10 of phosphonate

0.86

O26 of cyclic_hydroxyl

O10 of phosphonate

0.85

N33 of cyclic_amide_2

O10 of phosphonate

0.79

N11 of phosphinic_amide

O41 of acyclic_hydroxyl 0.58

O41 of acyclic_hydroxyl

O41 of acyclic_hydroxyl $\quad 0.56$

O26 of cyclic_hydroxyl

O41 of acyclic_hydroxyl $\quad 0.54$

N11 of phosphinic_amide

O39 of cyclic_amide_2 0.52

O41 of acyclic_hydroxyl

O39 of cyclic_amide_2 0.5

O26 of cyclic_hydroxyl

O39 of cyclic_amide_2

0.48 
BUTYL ACETATE

O26 of cyclic_hydroxyl

N11 of phosphinic_amide

N33 of cyclic_amide_2

O26 of cyclic_hydroxyl

N11 of phosphinic_amide

O26 of cyclic_hydroxyl

N33 of cyclic_amide_2

O26 of cyclic_hydroxyl

N11 of phosphinic_amide

N11 of phosphinic_amide
O10 of phosphonate

0.88

O10 of phosphonate $\quad 0.88$

O10 of phosphonate $\quad 0.83$

O47 of acyclic_ester $\quad 0.62$

O47 of acyclic_ester $\quad 0.6$

O39 of cyclic_amide_2 0.52

O47 of acyclic_ester $\quad 0.51$

O17 of acyclic_ester $\quad 0.5$

O39 of cyclic_amide_2 0.5

O17 of acyclic_ester $\quad 0.48$

\begin{tabular}{lll}
\hline ANISOLE & & \\
O26 of cyclic_hydroxyl & O10 of phosphonate & 0.87 \\
N11 of phosphinic_amide & O10 of phosphonate & 0.87 \\
N33 of cyclic_amide_2 & O10 of phosphonate & 0.83 \\
O26 of cyclic_hydroxyl & O39 of cyclic_amide_2 & 0.48 \\
N11 of phosphinic_amide & O39 of cyclic_amide_2 & 0.48 \\
O26 of cyclic_hydroxyl & O17 of acyclic_ester & 0.46 \\
N11 of phosphinic_amide & O17 of acyclic_ester & 0.45 \\
N33 of cyclic_amide_2 & O39 of cyclic_amide_2 & 0.41 \\
N33 of cyclic_amide_2 & O17 of acyclic_ester & 0.38 \\
O26 of cyclic_hydroxyl & O26 of cyclic_hydroxyl & 0.34 \\
\hline
\end{tabular}




\section{ACETONE}

O26 of cyclic_hydroxyl

N11 of phosphinic_amide

N33 of cyclic_amide_2

O26 of cyclic_hydroxyl

N11 of phosphinic_amide

N33 of cyclic_amide_2

O26 of cyclic_hydroxyl

O26 of cyclic_hydroxyl

N11 of phosphinic_amide

N11 of phosphinic_amide
O10 of phosphonate

0.87

O10 of phosphonate

0.86

O10 of phosphonate

0.82

O43 of acyclic_carbonyl $\quad 0.66$

O43 of acyclic_carbonyl $\quad 0.65$

O43 of acyclic_carbonyl $\quad 0.57$

O17 of acyclic_ester $\quad 0.51$

O39 of cyclic_amide_2 0.51

O17 of acyclic_ester $\quad 0.5$

O39 of cyclic_amide_2 0.49

\section{THF}

O26 of cyclic_hydroxyl

O10 of phosphonate

0.86

N11 of phosphinic_amide

O10 of phosphonate

0.86

N33 of cyclic_amide_2

O10 of phosphonate

0.79

O26 of cyclic_hydroxyl

O39 of cyclic_amide_2

0.51

N11 of phosphinic_amide

O39 of cyclic_amide_2 0.51

O26 of cyclic_hydroxyl

O17 of acyclic_ester

0.47

N11 of phosphinic_amide

O17 of acyclic_ester

0.46

N33 of cyclic_amide_2

O39 of cyclic_amide_2 0.39

O26 of cyclic_hydroxyl

O26 of cyclic_hydroxyl $\quad 0.38$

N11 of phosphinic_amide

O26 of cyclic_hydroxyl $\quad 0.37$

O26 of cyclic_hydroxyl

O38 of cyclic_amide_2 0.36

N11 of phosphinic_amide

O38 of cyclic_amide_2 0.35

N33 of cyclic_amide_2

O17 of acyclic_ester

0.35

O26 of cyclic_hydroxyl

O42 of cyclic_ether_1

0.34 


\section{ETHYL ACETATE}

O26 of cyclic_hydroxyl

O10 of phosphonate

0.89

N11 of phosphinic_amide

O10 of phosphonate

0.87

N33 of cyclic_amide_2

O10 of phosphonate

0.83

O26 of cyclic_hydroxyl

O45 of acyclic_ester

0.64

N11 of phosphinic_amide

O45 of acyclic_ester

0.6

O26 of cyclic_hydroxyl

O39 of cyclic_amide_2 0.55

N33 of cyclic_amide_2

O45 of acyclic_ester $\quad 0.54$

O26 of cyclic_hydroxyl

O17 of acyclic_ester $\quad 0.52$

N11 of phosphinic_amide

O39 of cyclic_amide_2 0.5

N11 of phosphinic_amide

O17 of acyclic_ester

0.47

\section{SOLUTION BASED EXPERIMENTS}

Table S4. Results from solution-based experiments.

\begin{tabular}{|c|c|c|}
\hline Solvent & Slow evaporation & Cooling crystallization \\
\hline methanol & amorphous & amorphous \\
\hline acetone & amorphous & amorphous \\
\hline anisole & Single crystals of form 1 & Single crystals of form 1 \\
\hline butyl acetate & amorphous & amorphous \\
\hline chloroform & amorphous & amorphous \\
\hline tetrahydrofuran & amorphous & amorphous \\
\hline water & amorphous & amorphous \\
\hline ethyl acetate & amorphous & amorphous \\
\hline
\end{tabular}




\section{CRYSTAL STRUCTURES}

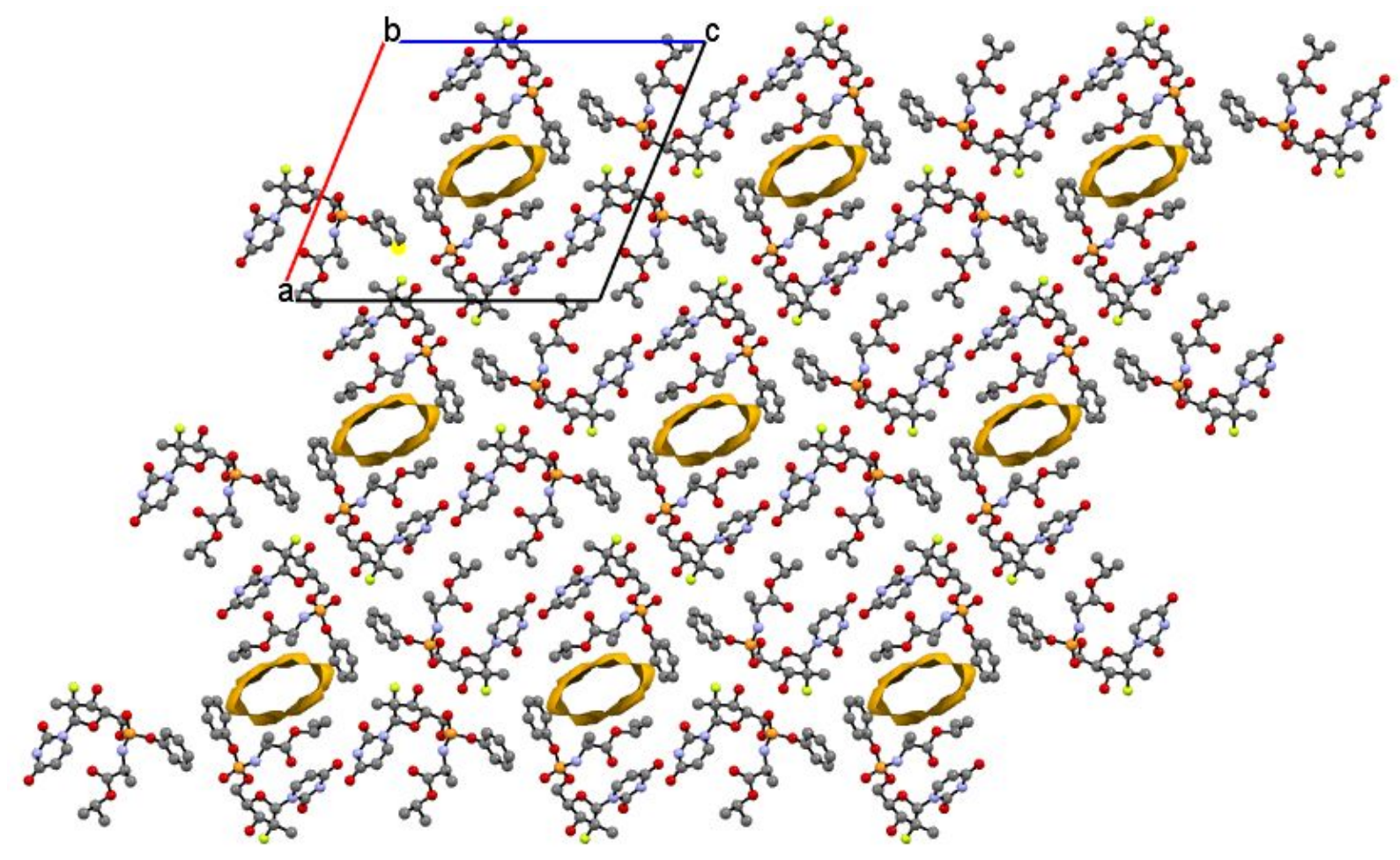

Figure SI 19. Illustration of the pores inside the structure of sofosbuvir form 1 (view down crystallographic b axis). Axis b is represented with red colour, c with blue colour and a with green colour. 


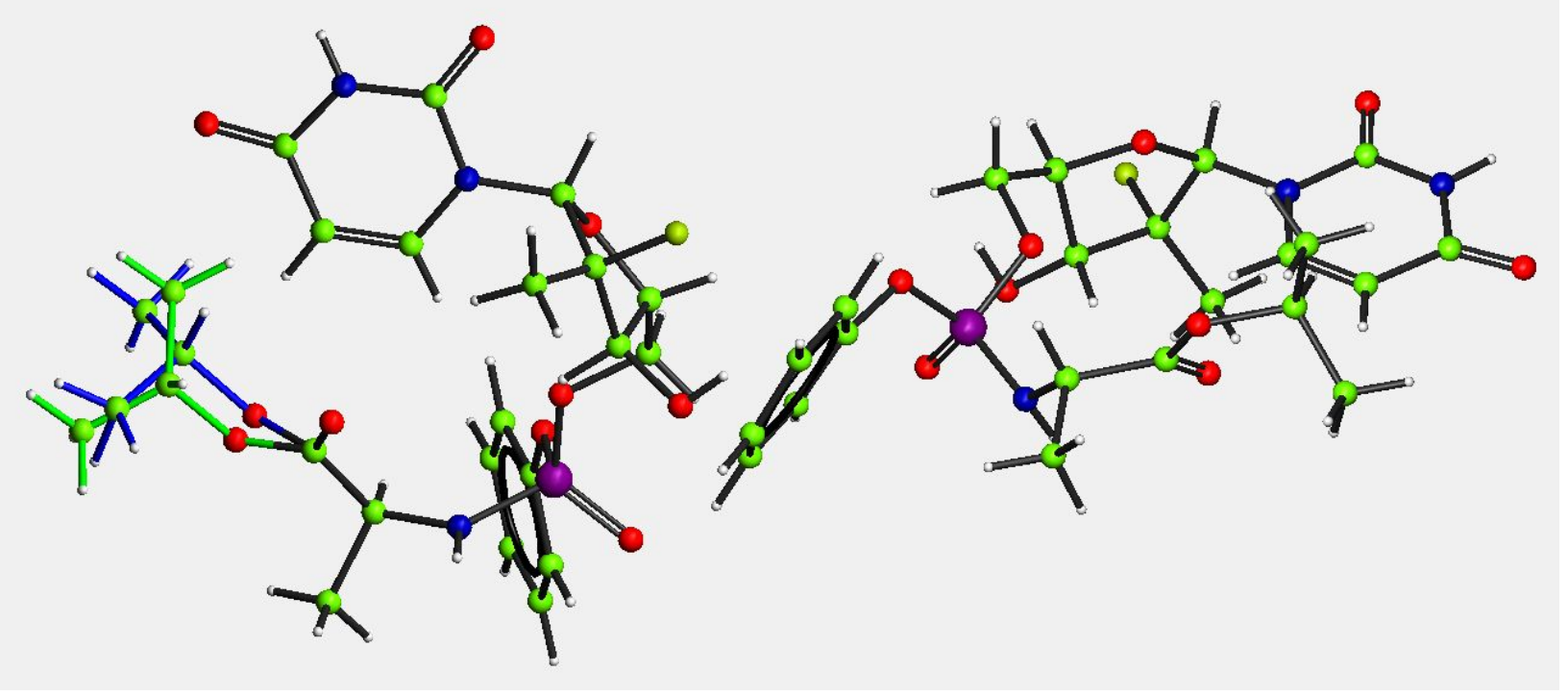

Figure SI 20. Disorder in form 1 of the sofosbuvir on left molecule. Two different structures are illustrated by green and blue connections in-between atoms.

\section{INFO ABOUT THE GRINDING JARS}

The jars that were used in this work are commercially available from the company FORM-TECH SCIENTIFIC. They are the SMARTSNAPTM GRINDING JARS and they have the close and seal design. This means that they are easy to use and provide a hermetic seal, as the manufacturers describe in the information of the product. To ensure that we were able to trap the solvents we compared with similar vials $(5 \mathrm{ml})$ from another commercial supplier (Retch), that they are simple, and they don't provide the hermetic sealing. We observed that when we performed experiments with acetone, with the smartssnap jars we had transformation to an amorphous form while with the other jars form 1 remained form 1 . This proves that the jars we selected for our experiments were suitable to trap the low boiling point solvents. Regarding the dimensions of the jar, the diameter is $1,1 \mathrm{~cm}$ and internal diameter and internal length is $4 \mathrm{~cm}$.

\section{REFERENCES}

1 R. Černý, V. Favre-Nicolin, J. Rohlíček, M. Hušák, R. Černý, V. Favre-Nicolin, J. Rohlíček and M. Hušák, Crystals, 2017, 7, 322.

2 V. Petříček, M. Dušek and L. Palatinus, Zeitschrift für Krist. - Cryst. Mater., 2014, 229, 345-352.

3 A. Esmaeili, T. Kamiyama, R. Oishi-Tomiyasu and IUCr, J. Appl. Crystallogr., 2017, 50, 651-659. 